\title{
The Health and Wealth of Mountain Communities
}

\author{
Nancy P. Chin ${ }^{1}$ Timothy D. Dye ${ }^{2}$
}

Published online: 17 November 2016

(C) Springer Science+Business Media New York 2016

According to the United Nations, $13 \%$ of the world's population live in mountain communities, representing 915 million people (Food and Agricultural Organization of the United Nations 2015). Mountains are critical to the health of the planet: their rivers are the source of much of the world's fresh water for household use, irrigation systems, industry, and electricity; mountains are repositories of plant and animal biodiversity, including species unique to high altitudes. Many high-altitude plants have medicinal uses and are often the only source of medication for mountain dwellers isolated from health care. Mountains serve as sites of recreation, leisure, and renewal. Mountains often have religious significance and host pilgrims from all over the world. People who traditionally live in mountain communities provide crucial management of this fragile ecological niche. Without human communities to maintain waterways, forests, wildlife, agricultural lands and the like we lose species diversity, promote the risk of flooding in the valleys, and risk contaminating our fresh water supplies for downstream communities. We need mountain communities to flourish.

Right now people in mountain areas are beset by a number of problems which threaten their health including water scarcity associated with climate change, desertification, increasing natural disasters in part due to ill-advised

Timothy D. Dye

tim_dye@urmc.rochester.edu

1 Public Health Sciences, Medical Humanities, and Bioethics, University of Rochester School of Medicine and Dentistry, Rochester, NY, USA

2 Obstetrics and Gynecology, Pediatrics, and Public Health Sciences, Strong Memorial Hospital, University of Rochester School of Medicine and Dentistry, 601 Elmwood Avenue, Office 2.3248, Rochester, NY 14642-0708, USA development projects, and especially in the rural mountain areas of middle- and low-income countries, food insecurity and high rates of maternal and child mortality. Often mountain communities are politically marginalized and economically distressed. Yet globally we invest less and less in the development of mountain communities. It is time to invest in sustainable development for mountain communities. This needs to include improvements in maternal and child health.

The threats to health for mothers and children in mountain areas are multiple:

- Inadequate nutrition during pregnancy, especially with regards to micronutrients

- Heavy maternal work load, especially in the third trimester

- Malnutrition among children under 5 years of age

- Lack of well-trained health professionals

- Long distances to health services

- Hard to maintain infrastructures such as roads and bridges

Nevertheless, solutions to these issues may be found in the traditional systems of knowledge that have previously sustained populations in mountain areas for centuries. The combination of traditional knowledge systems with contemporary technologies, appropriate development strategies that includes community input, and use of evidence based programs adapted to local conditions can address the health problems facing women and children in mountain areas.

Between the two of us, we have worked in mountain communities throughout the world, in North, South, and Central America, the Caribbean, Africa, Europe, Asia and the Pacific, even Antarctica. Are there any themes that tie together communities in such wildly different regions of the 
world? The first thing that comes to mind is the lack of political power. Mountains are sparsely populated, with few voters, leaving them at the mercy of higher level economic and political forces that render their initiatives under-funded and their health services truncated. Even when services are working optimally to meet the health needs of the populations, they are threatened with termination, by moving essential health services to central locations far away to save money. This in turns discourages people from settling in small mountain towns, creating a vicious cycle of reduced services due to low population density, and then people relocating out of the area because there are no services. Pregnant women, in our experience, are especially sensitive to the relocation of maternity services. The unintended consequence of centralizing services is that people move away from villages and crowd the towns. Although service delivery is difficult to maintain in the mountains, it is not impossible.

The second thing that comes to mind when considering what mountain communities have in common is the contrast between struggling families and the sometimes wealthy tourist and adventure-seekers that move through mountain towns on vacation or with expeditions. Is there no sense of social responsibility to those who serve by those who are served? Sir Edmund Hillary is a notable exception to this pattern. After his team ascended Everest, he took a long hard look at the families and communities of Sherpas that supported the climb. He built schools, models for education in the region. Are $\mathrm{MCH}$ health indicators better in these villages than other comparable mountain towns? Is there a way for mountain communities to partner with travelers to support local health and education programs?

Third, as with islands and other geographically and socially isolated locales, mountain communities emerge in a particular physical context that shapes its peoples linguistically, culturally, and biologically. People, plants, and animals evolve together within a particular environment that, over centuries, shapes health and well-being. When removed from this ecological context or when the ecology is disrupted, mountain people suffer health consequences that could differ greatly from the larger regions and nations of which they are a part. While the symbiosis and evolution of populations within particular environments applies to all communities throughout the world, this delicate but strong relationship seems more visible and pronounced in mountain environments where people can eat differently, think differently, and speak differently than lowlanders and persons living in other mountain communities.

Finally, the fourth theme that recurs in our work with mountain communities is how under-valued local expertise is. Most mountain people live in intimate contact with their landscape and constantly accrue information about it, explore the landscape, and are sensitive to subtle changes. In December 2014 in Ladakh's Zanskar valley, for example, local people noticed changes in the level of a nearby river. Although they alerted authorities that something was wrong, action wasn't taken. Local people then began to explore the situation for themselves and discovered a landside at a remote site had created an artificial lake. They recognized this as a dangerous situation and again alerted authorities. The army corps of engineers than took over and tried (unsuccessfully) to release water from the lake slowly to avert flooding. Although the dam subsequently burst and flooding did occur, there were no human causalities as a result of the flood. All people and livestock had been evacuated. Locals believe that if the engineers had worked more closely with the residents of the valley that better methods for release of water would have been instituted.

This Special Issue focused on Mountain MCH helps highlight the circumstances and special needs of mountain populations. Audsley et al. present an overview of the literature on mountain child health, highlighting the historical and particular circumstances that shape mountain communities and the health of children born in mountain environments. Letson et al. present a unique analysis of low birthweight infants in high-altitude Colorado, helping to identify and target preventive behaviors that could impact low birthweight in the mountain communities of the American Rockies. Several studies highlight the diverse needs across the Himalayas, with papers by Craig et al. on contraception and fertility in Nepal and by Prochaska et al. in the Indian Himalaya focused on skilled birth attendance, both underscoring the particular social and cultural milieu impacting populations in these mountain regions. Adams et al. and Chierici et al. present unique, community-driven maternal health programs in isolated regions of Nepal and Haiti, respectively. Innovations as described in these papers are essential to help meet the needs of women and their families living in oftentimes remote, isolated, and marginalized areas. The Special Issue closes with an analysis of adolescent pregnancy and smoking in the Appalachian state of West Virginia in the United States, highlighting ongoing challenges to prevention in rural mountain populations.

Taken together, the set of papers in this Mountain $\mathrm{MCH}$ Special Issue provide a brief and important glimpse into the strengths, challenges, and innovations that surround mountain maternal and child health. Not always strong in numbers, mountain populations present opportunities to learn more about our interface with geographies and topographies and the frequently unique circumstances that surround isolated and remote communities. Innovations that serve these populations can provide lessons for sensitive, appropriate, and effective care delivery in other marginalized populations we serve.

\section{Reference}

Food and Agricultural Organization of the United Nations (2015). Mapping the vulnerability of mountain peoples to food insecurity. Rome: United Nations. 